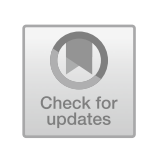

\title{
Justification of the Proposed Paradigm Shift
}

\begin{abstract}
This chapter goes into the benefits of the proposed perspective and approach. Arguments from various disciplines are offered to show the impact of a holistic perspective, for the individual, the community he/she lives in, and wider Society. A summary of evidence is drawn from the perspective of psychology and mental health, from biology, personal leadership and self-development, from evolutionary theories, from sociological argumentation, and from an economic viewpoint.
\end{abstract}

Keywords Interdisciplinary · Biology $\cdot$ Economy $\cdot$ Sociology · Optimization · Self-development

The benefits of a holistic understanding of human existence are widespread. The pursuit of systematic approaches that look at the interplay within and between the four systems is referenced in various disciplines. While the previous pages looked at the four dimensions that make up the individual (soul, heart, mind, and body), the second part of this book will look at the interplay between individuals and those around them. This examination will draw on evidence from psychology, biology, leadership tactics, evolutionary theories, sociology, and economic theory. Functioning as a bridge between these two parts, this chapter summarizes some of the advantages of life geared towards a meta-perspective. The following long, yet not exclusive, list of findings will show how scrutiny has discredited the commonly assumed and widely shared opinion that

(C) The Author(s) 2020

C. C. Walther, Development, Humanitarian Aid, and Social Welfare, https://doi.org/10.1007/978-3-030-42610-1_5 
the ego informs values related to survival and success. The Latin proverb 'homo homini lupus est' ('Man is wolf to man') (Plautus T.M. 254-184 $\mathrm{BC}$ ) is not rationally defendable. Everyone gains when individuals transcend the instinct of personal ambition.

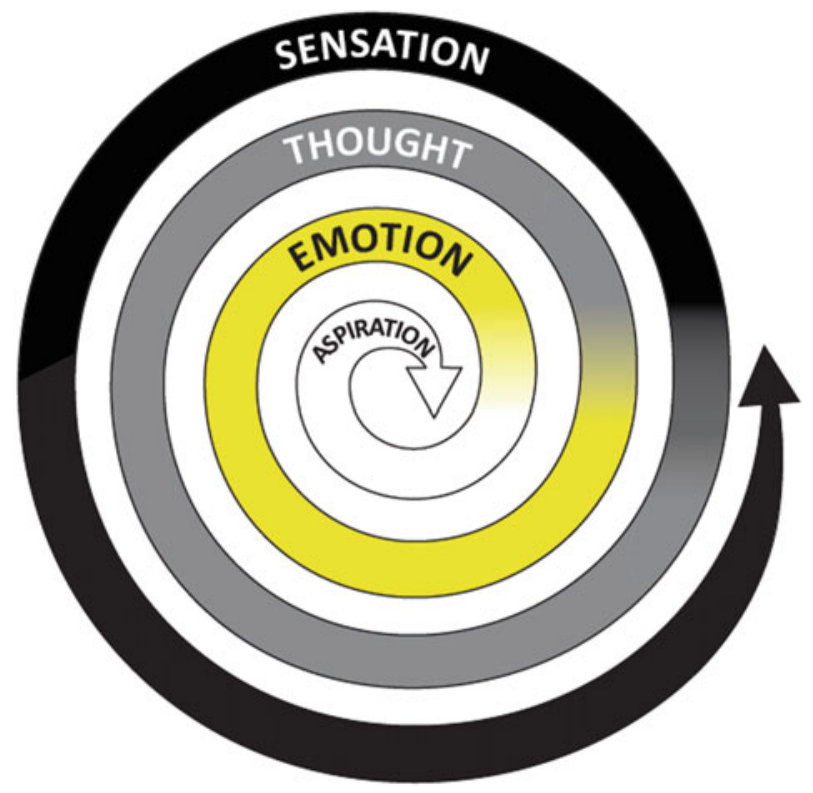




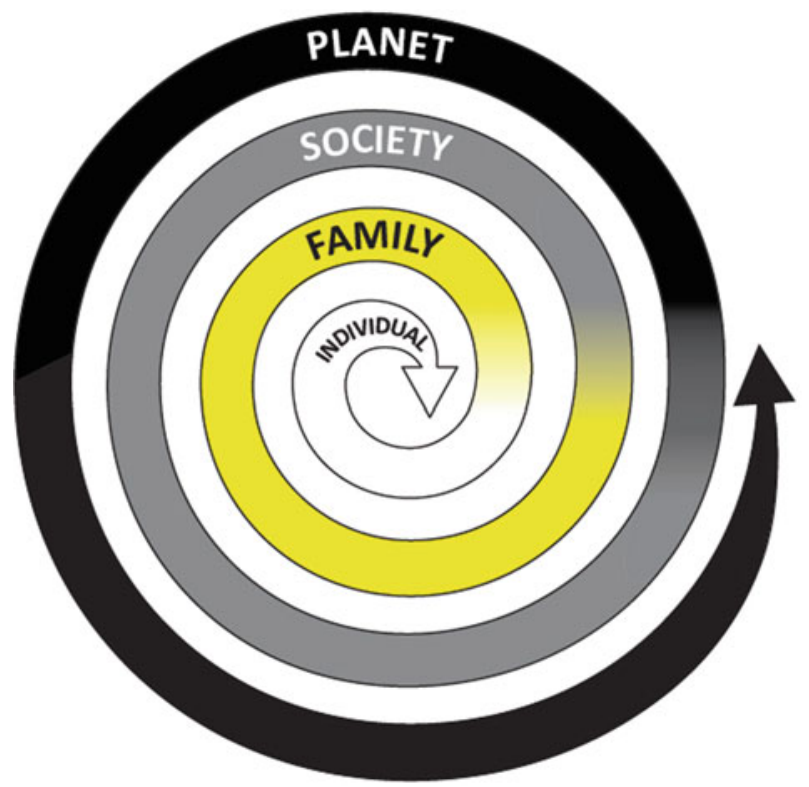

We will look here at the individual and collective benefits of changes that arise from an alignment of the four components described previously (purpose, compassion, honesty, and influence), and go on to explore a multidisciplinary approach to access these benefits. Based on the fourdimensional model described above, the approach involves individuals, the community they inhabit, and broader Society, with the understanding that all are part of the same meta-system. Beyond this individual sphere of application, we shall see why concentrating such self-development investments in an initial phase on aid organizations, young people, social workers, and the elderly generates a significant multiplier effect.

\section{Benefit Summary at Micro-, Meso- AND Macro-Levels}

Short- and medium-term results at the micro-level (i.e., changes 'from the inside') include increased levels of caring and compassion for oneself and others (Neff 2010), improved emotional stability (Chaturvedi and Chander 2010), a more positive life outlook (Carver et al. 2010), and 
better physical health, among other factors due to altered stress management strategies (Eric et al. 2017). When individuals improve their relationship to their inner self, their ability to feel and express compassion for others emerges. This improvement is enabled by a growing desire to help others without expecting something in return, ${ }^{1}$ combined with the growing understanding that all people, no matter their level of wealth, health, or literacy, have the power and responsibility to influence their circumstances. This changed perception of the self and others results in changed meso-systems. In turn, these transformed meso-levels impact the individual's subjective and objective well-being (Summers et al. 2012). The situation deriving from COVID-19 illustrates how fragile the Society that we all live in is. And how interconnected we are. Carefully and systematically nurturing micro, meso and macro environments that are conducive to the common good has never been as crucially relevant to our individual and collective survival as today.

Neuroscience shows that regular meditation practice impacts the physical brain structure while improving emotional intelligence and personal resilience (Tang et al. 2015). Researchers found a direct correlation between mindfulness practices and the increase of brain muscles within the brain/precuneus (Kurth et al. 2014), raising the subjective happiness scores of those who conduct practices (Sato et al. 2015). Science also indicates that connecting people to a purpose beyond their personal interests, such as taking action to help others, boosts their performance and overall contentment (Hagel et al. 2017). Mindful interactions following meditation resulted in improved working relationships in corporations that offered employees this type of practice (Goodman 2013). Taking this into account, staff meditation programs have become a standard resource at many leading corporations. ${ }^{2}$ It remains to be seen when aid organizations will get on the bandwagon. Seeing that such organizations' mission is, in the simplest terms, to make the World a 'happier' place, it seems logical that they must begin from within by investing in their staff's well-being. Nothing can be shared outside without first being found inside. Various researchers have shown that humanitarian aid workers face increased risk of various personal challenges including anxiety, burnout, depression, post-traumatic stress disorder (PTSD), and hazardous alcohol consumption. ${ }^{3}$ Despite such findings, so far neither non-governmental organizations nor the United Nations have put in place systematic programs for staff care and well-being in the field or at headquarters. It is important to consider the sector's efficiency, or lack thereof, in relation to the state of mind of its staff members. 
Intra- and interpersonal relationships shape organizational climates; both improve when individuals shift their focus from seeking problems to finding solutions. As a growing number of individuals and organizations widen their scope of attention beyond their immediate interests to the environment within which they operate, the weight of addressing issues becomes a shared burden that is lighter on everyone. Suddenly, challenges that previously seemed insurmountable feel less daunting, and they gradually become solvable. As individuals' emotional stability increases, they become sources of harmony in their families, communities, and Societies. This gradually increases the ability of these 'meso-systems' to withstand hardship. So-called resilience involves individual and environmental factors. It begins inside and is nurtured outside because individuals are connected and mutually dependent.

In the longer term, the holistic perspective proposed in these pages is favorable to the emergence of a new generation of social norms. ${ }^{4}$ Every individual action is part of a wider social dynamic. When people change their behavior, they also affect the social dynamics that they are part of. If they repeat this new behavior over time, it becomes a habit, gradually becoming part of their personality. It will influence both their own experience and how others experience them. If a critical mass of people adopt a new behavior pattern, and repeat it over time, the collective impact of this behavioral change amplifies the impact that everyone's action has had. Eventually, the social dynamic is not only altered by this direct double impact, but also by a third and indirect consequence.

The more people engage in a new habit over time, the more other people notice it. As the crowd expands, its appeal increases. Eventually, this leads to changes in the prevailing normative and empirical expectations, causing the general populace to comply with the new social standard because they feel or imagine a mounting social pressure to comply (Bicchieri 2006). Creating a nurturing Society is a slow and gradual process, just like all other natural processes. Nature does not reach its ideal outcomes when someone pulls a seedling up from the ground and stretches it to grow faster, but rather when one patiently cultivates the soil below, providing nutrients while respecting the plant's space and growth speed.

The methodology proposed here is in line with recent and current research in human psychology and is universally applicable. Its ultimate objective is to support a dynamic which contributes to subjective and collective well-being, or simply said, to support 'happy people in a happy 
Society'. The main aim of the following pages is to show the connection between individual happiness and collective happiness, how one nurtures the other, and how both become amplified and multiplied in turn.

There is no blueprint that suits everyone everywhere, no 'one size fits all'. One must always consider the prevailing culture and belief system in a particular Society or community. However, the following pages offer a succinct summarized overview of the benefits of the proposed paradigm shift in any Society, given the commonalities all people share through human nature. The list is not exclusive and represents merely an attempt to give points in support of a larger argument. It makes sense to the inner voice, yet stands against the traditional hypothesis of homo homini lupus est. While acknowledging that everyone can cause both, harm and happiness, the assumption of the herein proposed paradigm is that we have a choice. 'Potentiality and determination are different concepts. (...) Homo sapiens was both special and not special. [...] Humans are animals and everything we do lies within our biological potential' [...] This does not 'imply that our specific patterns of behavior and social arrangements are in any way directly determined by our genes' (Gould 1977). Awareness allows us to shift from lupus to lux-homo homini lux est (Latin 'Man is light for men').

Everything from aspiration to emotion to thought to experience is connected, as are individuals and Society. Identifying purpose and acting in line with this purpose is conducive to an individual's subjective well-being and is also indispensable for social progress. A Society with rules and resources that benefit everyone is conducive to individual and collective well-being.

\subsection{Benefits for the Individual}

From a mental perspective, a fulfilling life requires both happiness and meaning, two aspects that overlap only partially (Baumeister et al. 2013). Satisfaction of one's needs and wants increases happiness but is largely irrelevant to meaningfulness. Happiness is largely oriented toward the present, whereas meaningfulness involves integrating the past, present, and future. Happiness is frequently linked to being a taker rather than a giver. Meaningfulness is associated with being a giver rather than a taker. Personal identity and self-expression contribute to meaning but not to happiness. Action undertaken for others out of genuine compassion results in deep and lasting satisfaction because contributing to a cause 
beyond the personal ego generates happiness, a sense of meaning, and a feeling that one's wants have been satisfied.

From a psychological perspective, human beings are driven by the quest for meaning. ${ }^{5}$ Contributing to a cause greater than one's own interest is a precondition for the subjective perception of a fulfilling life. ${ }^{6}$ Humans strive for internal consistency. If one's thoughts, words, and action are in dissonance, one experiences subjective unhappiness even if objectively fulfilled in all factors of satisfaction such as health, wealth, social standing, and entertainment. An individual who experiences 'cognitive dissonance"7 tends to become psychologically uncomfortable, becoming motivated to try to reduce this discomfort and to actively avoid situations and information deemed likely to increase the discomfort. Selfish behavior often causes dissonance, as it goes against the inherent human trait of cooperation as well as the religious values and social mores with which many are raised. Unless the individual becomes conscious of the cause of such discomfort, he/she will avoid situations and/or information that highlights the conflict between belief and action, rather than changing the related behavior (Harmon-Jones and Mills 2019).

Positive psychology's creator Dr. Martin Seligman considers lasting happiness the combined result of: a pleasant life, defined as a life that successfully pursues positive emotions about the present, past, and future; the engaged life, defined as using our signature strengths to obtain abundant gratification through activities that we enjoy in the major dimensions of life; and the meaningful life, defined as using our signature strengths and virtues in the service of something much larger than ourselves (Seligman 2002).

From a biological perspective, the brain is wired to respond to suffering and derives pleasure from alleviating this suffering. ${ }^{8}$ The same part of the brain that is attuned to personal suffering is activated when subjects contemplate the suffering of others. ${ }^{9}$ Helping others triggers activity in the caudate nucleus and anterior cingulate portions of the brain, which are also activated when people gratify a personal desire. The individual can get the same flow of so-called pleasure hormones by alleviating someone else's suffering as from buying a new gadget or indulging in chocolate. Along the same lines, when the individual feels compassion for others, this emotion generates physiological changes conducive to making the person stay and help. This functions as an opposite to the fight-or-flight response that is activated when we feel threatened. Preparation to fight a threat or flee causes the heart and breathing rates to increase. This is 
an automatic reaction of the autonomic nervous system (ANS), a loose association of glands, organs, and cardiovascular and respiratory systems. These systems play a vital role in regulating blood flow and breathing patterns for different kinds of actions. An individual's heart rate does not rise upon perceiving others' suffering, but rather falls below the baseline levels, preparing him/her not to fight or flee, but to approach and soothe.

From a physiological perspective, research proves that the state of mind influences the functioning and well-being of the body, and vice versa. For example, the state of muscles and breathing has a direct impact on mental stress. ${ }^{10}$ Studies show that consciously executed physical movement such as a regular yoga practice can prevent or alleviate physiological, emotional, and spiritual pain while improving respiratory and cardiovascular functions. Additionally, yoga has been proven a relevant tool in addiction treatment. Studies have shown that increasing awareness of one's body through conscious exercise, balanced nutrition, and breathing exercises help reduce anxiety, depression, and chronic pain while improving sleep patterns and overall well-being (Woodyard 2011). Certain practices involving several of the five senses, such as dance, are effective at increasing subjective well-being, mood, body image, and interpersonal competence while decreasing clinical symptoms of depression and anxiety (Koch et al. 2014).

From a spiritual perspective, the principle of doing to others what one wishes for oneself is found across many religions and cultures (The Christopher Newsletter 2006). Sometimes called the 'Golden Rule', this principle is woven through Christianity, Islam, Buddhism, Hinduism, and native beliefs, even appearing in Scientology and other modern spiritual movements. It is justified in various ways and rooted in multiple explanations. Beyond the immediate benefit of a positive action for the beneficiary, one might also consider the possibility of receiving reciprocal positive action. An individual's thoughts, words, and actions carry the seeds of his/her future (Krishan 1988) because everything generates energy that returns in kind. When one chooses to invest energy in others' happiness, the fruit of one's karma is happiness and success. Selfless service is a winwin-win-win. It benefits the one who acts, the one who is acted upon, and the one who observes the action being performed while having a positive impact on broader Society.

From a philosophical perspective, dualism is a mental construct that has come to shape our perception of reality. ${ }^{11}$ Overcoming this artificial conceptualization would allow us to see the complementarity of both spheres 
and therefore allow our perception of the four dimensions of our experience to emerge. Today's concept of dualism is closely associated with Rene Descartes and the sixteenth century. Descartes held that the mind is a non-physical, and therefore non-spatial, substance. He identified the mind with consciousness and self-awareness and distinguished it from the brain as the seat of intelligence. However, for some time now, there has been rising interest in the complementarity of both. As Pauli (1994) stated 'It would be most satisfactory for all if physic and psyche could be seen as complementary aspects of the same reality'.

From a rights-based perspective, every human being is born with rights and responsibilities. ${ }^{12}$ Rights are Universal as is the responsibility to act or to abstain from acting, according to the rights of those around us. However, there are degrees and variations that derive from the individual's situation. While the fundamental needs, rights, and responsibilities are the same for all human beings, the level of responsibility and the weight of certain needs depend on individual circumstances. In this logic of interdependence between rights and responsibility, of have and have not, the rights of the disadvantaged person acquire an expanded dimension. This dimension pertains to a disadvantaged person's entitlement to a change that would restore the functionality of an unfulfilled right; this dimension correlates with a responsibility dimension that is linked to the privileges the more fortunate hold. The intensity of this responsibility dimension increases with the means of its holder. Having or acquiring possessions, power or skills, amplifies the responsibility of the privileged individual to use this advantage for the benefit of others. This inherent responsibility is not limited to the conventional pair of duty-bearer and rights-holder and cannot be transferred to the government or an institution (Walther 2014).

From an astral perspective, all is one. Every living organism contributes to the functioning of something else and the overall ecosystem. This symbiosis is neither good nor bad (Hanh 2008); rather, it is a law of nature like gravity or photosynthesis. This principle of interconnectivity is confirmed in quantum physics, wherein any physical object is made up of the same waves and particles, which correspond to each other in a duality of mind and matter (Morales 1999). 


\section{Benefits for Society-From Subjective Well-Being to Collective Welfare}

Starting with Plato, philosophers over millennia have contemplated the separation of mind and matter, which could be seen as a microrepresentation of the individual and Society. However, quantum physics offers scientific evidence that mind and matter are more than just connected; they are essentially the same thing (Atmanspacher 2004). The same separation in the perspective that most of us hold of ourselves, of our relationship to the institutions and communities we evolve in, and of the wider World, affects our relationship with nature with increasingly negative consequences. Everything is connected.

Climate change resulting from pollution, deforestation, and overuse of natural resources is just one of many calamities that illustrate the benefit of reversing the status quo and shifting the perspective from fragmentation to unification; from 'me' to 'us'. Drawing further on this example of humans and nature, studies show that individuals who live in close connection with nature report greater self-acceptance, increased social integration, more positive emotions, and greater life satisfaction (Mayer et al. 2009; Howell et al. 2011). Humans who have a close relationship with nature understand the immensity of the World and yet are able to relate this with feelings of personal autonomy, purpose, and growth. Indeed, the prevailing disconnect between many humans and the natural World appears to go against biophilia, humans' innate need to interact with other life-forms such as plants and animals (Wilson 1984). Associating with nature, rather than acting as an entity that exists independently in nature, is an important component of solving social and environmental problems (Dickinson 2013).

An understanding of the four dimensions that make up who we are, and which are mirrored by the social setting in which we evolve, nurtures awareness of the connection that binds us to nature. Establishing this awareness, however, requires mental space, which is consciously dedicated to a big picture perspective. Habitually, we function on autopilot, confusing short-lived pleasure with happiness (Weor 2013). Our challenge is to extend brief moments of insight into an uninterrupted presence that is marked by awareness.

Finding balance through inner stillness provides a complementary state of mind, which may compensate for the ceaseless exposure to external 
stimuli that often characterizes our existence in Society. It is in these precious moments of inner solitude that we know what really matters. When the razzle dazzle of external pushes and pulls, and the corresponding cravings and contradictions subside, the polar lodestar of purpose appears on the mental horizon.

When we manage to snap out of the loop that links action and reaction, input and output, we feel what we already knew: that the pursuit of status and material assets does not result in lasting contentment. The benefit of the perspective that is proposed in the present pages is not to teach new skills. Nor does it promise a new technology to solve the prevailing social ailments. This book merely seeks to show what belongs together, and why this connection matters for individuals and social prosperity.

From a sociological perspective, building a Society that is characterized by compassion begins at the core. People have many different needs, ranging from food and shelter, through safety, personal growth, and love, to approval from others, self-worth, and creativity (Hultman 1979). A person's belief system conditions the behavior one undertakes to meet these needs. Beliefs are the sum total of a person's experiences. They include all the lessons of life, including teachings about how to perceive the World and about what is right or wrong, good or bad. Over time, political systems tend to institutionalize the dominant values. Consequently, social innovation usually comes from sources outside of the prevailing governance system, such as social movements created by individuals (Castells 1972). It is crucial to instill in individuals the belief in the fundamental importance of social responsibility and kindness to personal and collective prosperity from a young age. Children must grow up in an environment that nurtures their instinct for cooperation. Behaviors derived from this understanding result in a certain type of experience that further affirms this initial perspective. As this behavior is maintained and pursued over time, it shapes the neural set-up of the organism. In this context, the organism is the physical stage of the individual's presence in Society, and our neural set-up is both cause and consequence of our worldview.

There are many clear benefits to pursuing collective well-being even beyond the immediate benefit of increased subjective well-being from the emission of oxytocin, one of several so-called 'happiness hormones' (Ryan 2018). Acts of kindness and the pursuit of a World that covers everyone's needs are in everybody's interest, psychologically and physiologically. The more unequal a Society is, the worse everyone's place in that Society is (Wilkinson and Pickett 2009). As stated eloquently by Wilkinson and 
Pickett (2009), there are 'pernicious effects that inequality has on societies: eroding trust, increasing anxiety and illness, and encouraging excessive consumption'. They demonstrate that in more unequal countries, the quality of life is significantly lower for everyone, rich or poor. Assessed factors include physical and mental health, substance abuse, benefits of education, conflict with the law, social-mobility, community coherence and trust, levels of violence, number of unwanted teenage pregnancies, and overall child well-being. And yet action to counteract the evergrowing inequality that marks the twenty-first century has to date been inadequate. One reason for this open-eyed blindness to our circumstances may be seen in an inadequate comprehension of the deep-seated impact of inequality on individuals and Society at large (Vandermoortele 2019)

By investing in inner peace, POZE is a down-payment toward collective social harmony. Awareness of the interplay between internal and external factors is an important condition for the first effective step from reflection to action, which involves thinking about reflexivity or action. The one who thinks will act to implement the learning that has resulted from that reflection and from the reactions of others to this change of direction (Soros 1987). This step from mind to materialization is important because the ideas generated by the process of reflection do not in and of themselves change how we act. It also matters for the one who thinks and acts, because through the physical execution of the idea, new experiences arise that result in new memories that will guide future behavior. With each new way of 'doing', a different set of neurons is activated. Repetition gradually results in a modification of the existing mental 'hardware' and the prevailing neuropathways change (Doidge 2007). As the physical act is performed, pursuing the new mental and behavioral path becomes easier with each repetition. Eventually, this complementarity of mind and matter, of thought/belief and action, becomes permanent. Like a stone thrown into water causes ripples, a changed mindset changes the individual's behavior, which circles out toward his/her community, which is part of a country, which is part of the international community and Planet. Over 7 billion stones can ripple-up any ocean. A spiral dynamic enters in motion.

From an evolutionary perspective, an organism is said to behave altruistically when its behavior benefits other organisms, at a cost to itself (Okasha 2003). These costs and benefits are measured in terms of reproductive fitness. By behaving altruistically, an organism reduces the number of offspring it is likely to produce itself but boosts the number that 
other organisms are likely to produce. This biological notion of altruism is not identical to the everyday concept in which an action would only be called 'altruistic', if it was done with the conscious intention of helping others. In the biological sense, there is no such requirement. ${ }^{13}$ From a Darwinian perspective, the existence of altruism seems surprising, as it puts the one who behaves altruistically at a disadvantage vis-à-vis the one which behaves selfishly. Imagine that some members of a group of Vervet monkeys give alarm calls when they see predators, but others do not. By refusing to give an alarm call, a monkey can reduce the chance that it will be attacked, while at the same time benefiting from the alarm calls of others. However, natural selection does not favor those monkeys that do not give alarm calls over those that do. Altruistic behavior has shown that individuals who act in ways that appear to be contrary to their own interests while benefiting someone else have advantages for their genetically similar kin (McAndrew 2002).

Organisms have economic lives as well as roles as replicators. In the broader context, individuals and populations belong to a species that are parts of a wider dynamic. They belong to communities that in turn exist and change in fluctuating environments. In a predominantly selfish tribe, altruism would be deselected. However, as altruistic behavior increases, the overall fitness of the group is affirmed. Groups with the highest proportion of altruists outperform the more selfish ones (Nowak and Highfield 2012). 'Individual fitness' thus extends to embrace 'inclusive fitness' of the kin group. In the long run, the success of the ephemeral individual is inextricably bound to the success of the group and ultimately of the entire species. It is not clear how 'quickly' a species evolves, and thus how long it takes for drastic shifts to happen.

Two ways to look at it are gradualism and punctuated equilibrium. Species can evolve by either or both (New England Complex Systems Institute 2019). Gradualism is selection and variation that happens slowly. Over a short period of time, it is hard to notice. Small variations that fit an organism slightly better to its environment are selected for: a few more individuals with more of the helpful trait survive, and a few more with less of the helpful trait die. Very slowly, in small increments, over a long time, the population changes. Change is slow, constant, and consistent. In punctuated equilibrium, change comes in spurts. There is a period of very little change, and then one or a few huge changes occur, often 
through mutations in the genes of a few individuals. Mutations are random changes in the DNA that are not inherited from the previous generation but are passed on to generations that follow. Though mutations are often harmful, those that result in a new punctuated equilibrium are very helpful to the individuals in their environments. Because these mutations are so different and so helpful to the survival of those that have them, the proportion of individuals in the population who have the mutation/trait increases over a very short period. The species changes rapidly (in terms of evolutionary time) and then settles down again for a comparatively long period of little change. The transformation can be either the cause of mutations or other causes, such as huge and sudden changes in the environment that result in more rapid changes in the organisms through harsher selection.

How did the tiger get its stripes: gradualism or punctuated equilibrium? Or a combination of both? Scientists think that species with a shorter evolution like humans evolved mostly by punctuated equilibrium, while those with a longer evolution evolved mostly by gradualism. Both contrast with the theory of variable-speed evolution, which maintains that different species evolve at different rates, and that there is no reason to stress one rate of change over another. ${ }^{14}$ Maybe it was not either/or, but a combination, a mutation resulted in very distinct, stripe-like markings, which were then gradually 'polished up' into stripes because the marked tigers fared so much better in the survival game because they were much better disguised. The point here is that social transformation can be slow and gradual, like the shift that led many countries from the 'normality' of women as prime caretakers to the 'normality' of women as equal business partners; or it can be the result of drastic land-shifts, like the 2010 Earthquake in Haiti which led, for a short period in time, to the arousal of solidarity at mass scale. Like the stripes of the tiger, a change of the present Society can happen gradually but must begin with certain drastic changes at the individual level.

The philosophical, biological, and social debate over the basic nature of humans as being 'universally selfish' or 'universally good' continues today, highlighting extremely divergent views of the natural social order. Are we naturally selfish or do we evolve to be so, because of Society? It seems that neither position is entirely correct, and, more importantly, nothing is cast in stone. Evolutionary studies have found that genetics only partially influence altruistic behavior (Reuter et al. 2010), whereas progress in biology, genetics, and neuroscience offer ever more evidence 
of the features and neuro-circuitry of the human brain which underlie our behavior in the selfish-selfless spectrum (Sonne and Gash 2018). Today's evidence supports the idea that altruistic potential is developed as a common feature in human populations. Comparing the critical features of the social brain along the scale from selfish-selfless behavior, from unemotional psychopaths to zealous altruists who take extreme measures to help others, one can see common behavioral traits and functional neural features. Herein both, genetic inheritance and cognitive learning, play important roles. Studies of diverse population groups, including newborns, adopted children, incarcerated juveniles, twins, and mindfulness meditators, point to the central role of neuroplasticity and the dopaminergic reward systems in forming and reforming neural circuitry in response to personal experience, as well as cultural influences in determining behavior in the selfish-selfless spectrum.

Studies show the underlying neural circuitry differs between psychopaths and altruists, with emotional processing being profoundly muted in psychopaths and significantly enhanced in altruists. Both groups are characterized by the reward system of the brain shaping behavior. Cognitive therapy as well as social and cultural experience, combined with approaches such as mindfulness training for introspection and rewardactivating compassion, can amend the existing circuit gradually, hereby changing the behavior that is both consequence and cause of these circuits. These approaches are slowly entering the mainstream of clinical care for managing pain, depression, and stress (Sonne and Gash 2018). Individuals, and hereby populations can migrate from one side of the behavioral spectrum to the other, in response to a holistic approach that addresses the four dimensions that make up who and how they are. As stated by Gould, 'Our genetic makeup permits a wide range of behaviors'-from altruism to xenophobia, from ego-centricity to extreme generosity. Upbringing, culture, class, status, and all the intangibles that we call "free will" determine how we restrict our behaviors from the wide spectrum-extreme altruism to extreme selfishness-that our genes permit (Gould 1977).

Like a gigantic puzzle, the diversified pieces of our existence are meant to fit together, no matter how far apart they are dispersed. All humans have the potential to thrive. Whether we develop this potential or not depends on circumstances, but more importantly, the choices that we consciously make along the way. No matter which context we evolve in, being aware of the desired destination is an absolute necessity, if we do 
not want to merely wander aimlessly but find satisfaction along the way. If we are blind to the what and why of our life, it is pointless to spend time and energy on the how. While obvious when put on paper, it is remarkable how prevalent the imbalance of modalities versus content is in our Society.

\section{Benefits for Society Plus-From Collective Welfare to Global Prosperity}

From an economic perspective, awareness to the connection that exists inside us and shapes our relationship with others opens space for a higher level of reflexivity. Perceiving ourselves as a minuscule yet unique and inseparable part of a complex, sensitive, and finely tuned Universe changes the outlook and attitude that we have toward ourselves and others.

A 'triple reflexive'15 is activated when the person experiencing an action understands and overcomes the simple reflexive response, which results from the interplay of action and reaction as illustrated by Pavlov's dog. The second reflexive, which operates with self-interested motivation, recognizes opportunities and weaknesses in others to be exploited for personal benefit. Finally, within the triple reflexive, the person understands that he/she is not bound to respond either way but can act in a manner that promotes cooperation within a group or build companionship with those who could have been taken advantage of. This outlook allows the emergence of a differentiated set of economic players with drastically different preferences. A holistic perspective nurtures the shift away from consumption, waste, and exploitation. Micro-, meso-, and macro-systems are subject to constant change, which allows for a diversified set of economic players to intervene, and to interact with each other within a continued meta-space.

From the meta-perspective, the idea of connection has been acknowledged since the beginning of time; therefore, the question is no longer to prove it, but to make the best of this connection for all the involved parties. In the eighteenth century, Johann Gottlieb Fichte stated a principle similar to the Butterfly Effect mentioned in the previous chapter: 'you could not remove a single grain of sand from its place without thereby changing something throughout all parts of the immeasurable whole'. This image of intrinsic connection of everything and everyone echoes the understanding of ancient philosophers and scientists, underpinning religions across the World. It has found its scientific expression in 'Chaos theory' which 
points out the sensitive dependence of a phenomenon on initial conditions. Even though the plan will not always yield results, a domino cascade can be consciously triggered. Wings of individual aspiration that are flapped today may unravel a history that is yet to be written.

Nature is intrinsically fine-tuned and, if left alone, functions within a self-balancing synchrony. This inherent balance that characterizes the human organism as much as the organic set-up of an algae, a tree, a seagull, or a chimpanzee is disturbed by those who are commonly called the peak of evolution. Human consciousness of some areas, without awareness of the bigger picture, and chosen blindness to the multiplicity of factors that are involved in our existence, leads us to unknowingly, intentionally, or recklessly disturb the laws that underpin the Universe. The bee does not visit flowers in order to carry pollen from one flower to the next; rather, these visits serve to collect honey; still, the consequence is that pollen is carried from one flower to the next, which enables the visited flowers to evolve and become fruits. No intention is involved, and yet seamless causation ensues.

The constant interplay of our aspirations, emotions, thoughts, and sensations shapes how we express ourselves in the World and how we experience it. The individual is a micro-representation of the Universe, which is continuously unfolding around us. These ongoing transformational dynamics impact ourselves and those around us. Vicious and virtuous circles are triggered and trigger each other like a Herculean machine where one gear's wheel turns the next cog; one being meshed with the other, each is turned by the one that is connected to it. Most changes that occur in our lives do not happen in order to make us reset our behavior. It is because they do occur that we adapt, change, and grow. Becoming aware of this unfolding flow does not equal control over it, but awareness of this flow is the first step toward understanding it. An understanding of the dynamics that shape our existence is needed to eventually influence them. Awareness to the spirals that never cease to turn in either direction opens our senses. Tuning into the rhythm of life is not a means to control the sequence of songs, but necessary to dance in synch with the music.

Human beings cannot bear limitless uncertainty (Grupe and Nitschke 2013). Religions manifest our long-standing desire to understand the unfolding immensity that marks our existence. They illustrate the human quest for meaning. Existing without grasping the point of everyday life is like floating in the open sea, without a shoreline, stars, or compass to guide us. 


\section{Notes}

1. Studies suggest that compassion may be self-perpetuating: Being compassionate causes a chemical reaction in the body that motivates an individual to be even more compassionate. When people perform behaviors associated with compassion (warm smiles, friendly hand gestures, affirmative forward leaning, etc.), their bodies produce more oxytocin, a hormone that promotes long-term bonds and commitments, as well as nurturing behavior-like care for offspring. See Keltner (2004).

2. Examples include Google, McKinsey, Nike, Apple, Twitter, Yahoo, Procter \& Gamble, HBO, Deutsche Bank, AOL, Heinz, etc.

3. For examples, see for burnout in organizational settings, Maslach and Jackson's (1984); Maslach et al. (1996); and for job burnout, Maslach et al. (2001); McCall and Salama (1999); and McCormack and Joseph (2012).

4. Research has shown that individuals conform with a social norm as an automatic response to cues in their situation that focus their attention on this particular norm, on condition that they expect sufficiently many in the population to follow the rule. Experimental research supports norm compliance, and the manipulation of such expectations can radically change behavior. Most subjects have a conditional preference for following prosocial norms. See Bicchieri (2006).

5. See Viktor Frankl, Man's Search for Meaning (1985), as well as version from Frankl with Lasch's translation (1992). Note-Predecessors of Frankl argued that the driving force is pleasure (Carl Jung) or power (Adolf Adler).

6. "Years of research on the psychology of well-being have demonstrated that often human beings are happiest when they are engaged in meaningful pursuits and virtuous activities." Refer to Kashdan et al. (2008).

7. Cognitive dissonance is the mental discomfort experienced by an individual who holds two or more contradictory beliefs, ideas, or values at the same time, and performs an action that is contradictory to one or more beliefs, ideas, or values, or is confronted by new information that conflicts with existing beliefs, ideas, or values. Refer to Festinger's (1962).

8. Refer to information regarding Joshua Greene and Jonathan Cohen of Princeton University in Keltner (2004).

9. Refer to James Rilling and Gregory Berns of Emory University in Keltner (2004).

10. Breathing affects the brain through signals carried by the vagus nerve. Not only does the vagus nerve send signals down to the heart, but it also carries signals up into the brain stem. Vagus nerve signaling activates circuits for resting and relaxation, known as the parasympathetic nervous system. 
The parasympathetic system is the opposite of the sympathetic nervous system, which controls the fight-or-flight instinct. Slow breathing increases activity in the vagus nerve and pushes the brain toward parasympathetic activity. On the other hand, fast shallow breathing increases excitement and anxiety. See Korb (2015).

11. Current thinking relies mostly on a dualistic perspective, whereby mind and body, individual and Society, tangible and intangible, inside and outside are separated. Mind-body dualism considers the mind and the body as distinct and separable. It encompasses a set of views about the relationship between mind and matter, and between subject and object, and is contrasted with physicalism and enactivism. Aristoteles shared Plato's view of various souls and explained hierarchy with distinctive functions for plants, animals, and people: a nutritive soul of growth and metabolism that all three share; a perceptive soul of pain, pleasure, and desire that only people and other animals share; and the faculty of reason that is unique to people only. For him, all three souls perish when the living organism dies, whereas for Plato the soul was not dependent on the physical body; he believed in metempsychosis, the migration of the soul to a new physical body, which corresponds to the belief of reincarnation found in Buddhism and Hinduism.

12. See in particular Universal Declaration of Human Rights, including Art. 22, Art. 26.

13. Some of the most interesting examples of biological altruism are found among creatures that are (presumably) not capable of conscious thought at all, e.g., insects. For the biologist, it is the consequences of an action for reproductive fitness that determine whether the action counts as altruistic, not the intentions, if any, with which the action is performed. Altruistic behavior is common throughout the animal kingdom, particularly in species with complex social structures. For example, vampire bats regularly regurgitate blood and donate it to other members of their group who have failed to feed that night, ensuring they do not starve. In numerous bird species, a breeding pair receives help in raising its young from other 'helper' birds, who protect the nest from predators and help to feed the fledglings. In social insect colonies (ants, wasps, bees, and termites), sterile workers devote their whole lives to caring for the queen, constructing and protecting the nest, foraging for food, and tending the larvae.

14. While Darwin is mostly quoted as seeing evolution as long, slow, and gradual, it should be noted that he did not put everything in the same box of speed. In the first edition of On the Origin of Species, Darwin stated that 'Species of different genera and classes have not changed at the same rate, or in the same degree'; he refined this in the fifth edition writing that 'the periods during which species have undergone modification, though long as measured in years, have probably been short in comparison with the 
periods during which they retain the same form'. See p. 84 of Gould and Eldredge (1972).

15. Term described by Marty Rowland at the Henry George School of Social Science memorandum on April 1, 2019, in New York.

\section{Works Cited}

Atmanspacher, H. (2004). Quantum approaches to consciousness. Stanford Encyclopedia of Philosophy.

Baumeister, R. F., Vohs, K. D., Aaker, J. L., \& Garbinsky, E. N. (2013). Some key differences between a happy life and a meaningful life. The Journal of Positive Psychology, 8(6), 505-516.

Bicchieri, C. (2006). The grammar of society: The nature and dynamics of social norms. Cambridge, UK: Cambridge University Press.

Carver, C. S., Scheier, M. F., \& Segerstrom, S. C. (2010). Optimism. Clinical Psychology Review, 30(7), 879-889.

Castells, M. (1972). La question urbaine. Paris: François Maspero.

Chaturvedi, M., \& Chander, R. (2010). Development of emotional stability scale. Industrial Psychiatry Journal, 19(1), 37-40.

Dickinson, E. (2013). The misdiagnosis: Rethinking "nature-deficit disorder". Environmental Communication: A Journal of Nature and Culture, 7(3), 315335 .

Doidge, N. (2007). The brain that changes itself: Stories of personal triumph from the frontiers of brain science. New York, NY: Viking Press.

Frankl, V. E. (1985). Man's search for meaning. New York: Simon and Schuster.

Frankl, V. E., \& Lasch, I. (1992). Man's search for meaning: An introduction to logotherapy. Boston, MA: Beacon Press.

Festinger, L. (1962). A theory of cognitive dissonance. Stanford, CA: Stanford University Press.

Goodman, P. S. (2013, July 18). Why companies are turning to meditation and yoga to boost the bottom line. The Huffington Post.

Gould, S. J. (1977). Biological potentiality vs biological determinism. In Ever since Darwin: Reflections in natural history (pp. 251-259). New York, NY: W. W. Norton.

Gould, S. J., \& Eldredge, N. (1972). Punctuated equilibria: An alternative to phyletic gradualism. In Models in paleobiology (pp. 82-115). San Francisco, CA: Freeman Cooper.

Grupe, D. W., \& Nitschke, J. B. (2013). Uncertainty and anticipation in anxiety: An integrated neurobiological and psychological perspective. Nature reviews: Neuroscience, 14(7), 488-501. 
Hagel, J., Brown, J. S., Wooll, M., \& Ranjan, A. (2017, June 6). If you love them, set them free. Retrieved from https://www2.deloitte.com/us/en/insights/ topics/talent/future-workforce-engagement-in-the-workplace.html.

Hanh, T. N. (2008). The world we have: A Buddhist approach to peace and ecology. Berkeley, CA: Parallax Press.

Harmon-Jones, E., \& Mills, J. (2019). An introduction to cognitive dissonance theory and an overview of current perspectives on the theory. In E. HarmonJones (Ed.), Cognitive dissonance: Reexamining a pivotal theory in psychology (pp. 3-24). American Psychological Association.

Hultman, K. (1979). The path of least resistance: Preparing employees for change. Austin, TX: Learning Concepts.

Howell, A. J., Dopko, R. L., Passmore, H. A., \& Buro, K. (2011). Nature connectedness: Associations with well-being and mindfulness. Personality and Individual Differences, 51(2), 166-171.

Kashdan, T. B., Biswas-Diener, R., \& King, L. A. (2008). Reconsidering happiness: The costs of distinguishing between hedonics and eudaimonia. The Journal of Positive Psychology, 3(4), 219-233.

Keltner, D. (2004). The compassionate instinct. Greater Good. University of California-Berkeley: UC Berkeley Center for the Development of Peace and Well-Being, Spring. Retrieved from https://greatergood.berkeley.edu/ article/item/the_compassionate_instinct.

Kim, E. S., Hagan, K. A., Grodstein, F., DeMeo, D. L., De Vivo, I., \& Kubzansky, L. D. (2017). Optimism and cause-specific mortality: A prospective cohort study. American Journal of Epidemiology, 185(1), 21-29.

Kristin, D. N. (2003). The development and validation of a scale to measure self-compassion. Self and Identity, 2(3), 223-250.

Koch, S., Kunz, T., Lykou, S., \& Cruz, R. (2014). Effects of dance movement therapy and dance on health-related psychological outcomes: A meta-analysis. The Arts in Psychotherapy, 41(1), 46-64.

Korb, A. (2015). The upward spiral: Using neuroscience to reverse the course of depression, one small change at a time. Oakland: New Harbinger Publications.

Krishan, Y. (1988). The Vedic origins of the doctrine of Karma. South Asian Studies, 4(1), 51-55.

Kurth, F., Luders, E., Wu, B., \& Black, D. S. (2014). Brain gray matter changes associated with mindfulness meditation in older adults: An exploratory pilot study using voxel-based morphometry. Neuro: Open Journal, l(1), 23.

Maslach, C., \& Jackson, S. E. (1984). Burnout in organizational settings. In S. Oskamp (Ed.), Applied social psychology annual: Applications in organizational settings (Vol. 5, pp. 133-153). Beverly Hills, CA: Sage.

Maslach, C., Jackson, S. E., \& Leiter, M. P. (1996). The Maslach burnout inventory-Test manual. Palo Alto, CA: Consulting Psychologists Press. 
Maslach, C., Schaufeli, W. B., \& Leiter, M. P. (2001). Job burnout. Annual Review of Psychology, 52(1), 397-422.

Mayer, F. S., Frantz, C. M., Bruehlman-Senecal, E., \& Dolliver, K. (2009). Why is nature beneficial? The role of connectedness to nature. Environment and Behavior, 41(5), 607-643.

McAndrew, F. T. (2002). New evolutionary perspectives on altruism: Multilevelselection and costly-signaling theories. Current Directions in Psychological Science, 11(2), 79-82.

McCall, M., \& Salama, P. (1999). Selection, training, and support of relief workers: An occupational health issue. British Medical Journal, 318(7176), 113116.

McCormack, L., \& Joseph, S. (2012). Postmission altruistic identity disruption questionnaire (PostAID/Q) preliminary development of a measure of responses following adverse humanitarian aid work. Traumatology, 18(3), 4148.

Morales, F. (1999). A comparative analysis of the Thomist and Vedantic perspectives on the ontology of self. Madison: University of Wisconsin-Madison.

New England Complex Systems Institute. (2019). Gradualism and punctuate equilibrium. Retrieved https://necsi.edu/gradualism-and-punctuatedequilibrium.

Nowak, M., \& Highfield, R. (2012). Supercooperators: Altruism, evolution, and why we need each other to succeed. New York: Simon \& Schuster.

Okasha, S. (2003). Biological altruism. Stanford Encyclopedia of Philosophy.

Pauli, W. (1994). The influence of archetypal ideas on the scientific theories of Kepler. In Writings on physics and philosophy (pp. 219-279). Berlin, Heidelberg: Springer.

Reuter, M., Frenzel, C., Walter, N. T., Markett, S., \& Montag, C. (2010). Investigating the genetic basis of altruism: The role of the COMT Val158Met polymorphism. Social Cognitive and Affective Neuroscience, 6(5), 662-668.

Ryan, O. (2018, March 30). Happiness hormones: How they differ and why it is important. Retrieved from https://thriveglobal.com/stories/happinesshormones-how-they-differ-and-why-it-is-important/.

Sato, W., Kochiyama, T., Uono, S., Kubota, Y., Sawada, R., Yoshimura, S., et al. (2015). The structural neural substrate of subjective happiness. Scientific Reports, 5, 16891.

Seligman, M. E. P. (2002). Authentic happiness: Using the new positive psychology to realize your potential for lasting fulfillment. New York, NY: Free Press.

Sonne, J. W., \& Gash, D. M. (2018). Psychopathy to altruism: Neurobiology of the selfish-selfless spectrum. Frontiers in Psychology, 9, 575.

Soros, G. (1987). The Alchemy of Finance: Reading the mind of the market. New York, United States: Simon and Schuster. 
Summers, J. K., Smith, L. M., Case, J. L., \& Linthurst, R. A. (2012). A review of the elements of human well-being with an emphasis on the contribution of ecosystem services. Ambio, 41(4), 327-340.

Tang, Y. Y., Hölzel, B. K., \& Posner, M. I. (2015). The neuroscience of mindfulness meditation. Nature Reviews Neuroscience, 16(4), 213-225.

The Christopher Newsletter. On "The Universality of the Golden Rule in the World Religions". (2006). Retrieved from http://www.teachingvalues.com/ goldenrule.html.

Vandermoortele, J. (2019). The open-and-shut case against inequality. https:// doi.org/10.1111/dpr.12484.

Walther, C. S. C. (2014). La responsabilité de rendre les droits des enfants une réalité. Marseille, France: University Aix-Marseille.

Weor, S. A. (2013). The great rebellion: The state of our world and how to change it through practical spirituality. Brooklyn, NY: Glorian.

Wilkinson, R. G., \& Pickett, K. (2009). The spirit level: Why more equal societies almost always do better. London: Allen Lane.

Wilson, E. O. (1984). Biophilia. Cambridge, MA: Harvard University Press.

Woodyard, C. (2011). Exploring the therapeutic effects of yoga and its ability to increase quality of life. International Journal of Yoga, 4(2), 49-54. 